\title{
Intestinal dysbiosis and reduced immunoglobulin-coated bacteria associated with coeliac disease in children
}

\author{
Giada De Palma', Inmaculada Nadal ${ }^{1}$, Marcela Medina', Ester Donat ${ }^{2}$, Carmen Ribes-Koninckx², Miguel Calabuig ${ }^{3}$, \\ Yolanda Sanz ${ }^{1 *}$
}

\begin{abstract}
Background: Coeliac disease is a chronic intestinal inflammatory disorder due to an aberrant immune response to dietary gluten proteins in genetically predisposed individuals. Mucosal immune response through IgA secretion constitutes a first line of defence responsible for neutralizing noxious antigens and pathogens. The aim of this study was the characterization of the relationships between immunoglobulin-coated bacteria and bacterial composition of faeces of coeliac disease (CD) patients, untreated and treated with a gluten-free diet (GFD) and healthy controls.
\end{abstract}

Results: IgA-coated faecal bacterial levels were significantly lower in both untreated and treated CD patients than in healthy controls. IgG and IgM-coated bacterial levels were also significantly lower in treated CD patients than in untreated CD patients and controls. Gram-positive to Gram-negative bacteria ratio was significantly reduced in both CD patients compared to controls. Bifidobacterium, Clostridium histolyticum, C. lituseburense and Faecalibacterium prausnitzii group proportions were less abundant $(P<0.050)$ in untreated $C D$ patients than in healthy controls. Bacteroides-Prevotella group proportions were more abundant $(P<0.050)$ in untreated $C D$ patients than in controls. Levels of IgA coating the Bacteroides-Prevotella group were significantly reduced $(P<0.050)$ in both CD patients in comparison with healthy controls.

Conclusions: In CD patients, reduced IgA-coated bacteria is associated with intestinal dysbiosis, which altogether provide new insights into the possible relationships between the gut microbiota and the host defences in this disorder.

\section{Background}

Coeliac disease $(\mathrm{CD})$ is a chronic intestinal inflammatory disorder triggered by the ingestion of gluten proteins in susceptible individuals. The active phase of the disease is characterized by a pro-inflammatory intestinal milieu resulting from an aberrant immune response to dietary gluten, along with increased epithelial permeability, which may favour the traffic of luminal antigens to the submucosa [1]. In CD patients, gliadin peptides can activate either an adaptive immune response dominated by $\mathrm{Th}_{1}$ pro-inflammatory cytokines (e.g. IFN- $\gamma$ ) within the mucosa or an innate immune response mediated by

\footnotetext{
* Correspondence: yolsanz@iata.csic.es

'Ecofisiología Microbiana y Nutrición, Instituto de Agroquímica y Tecnología de Alimentos (CSIC), Apartado 73, 46100 Burjassot, Valencia, Spain
}

IL-15, both of which lead to epithelial cell killing [2]. Gliadin also activates the zonulin pathway leading to an increase in intestinal permeability [1].

The aetiology of $\mathrm{CD}$ is multifactorial, involving genetic and environmental factors. This disorder is strongly associated to the human leukocyte antigen genes (HLA). Approximately $95 \%$ of the patients inherit the alleles encoding for the HLA-DQ2 and HLA-DQ8 molecules, but only a small percentage develops CD [3]. Studies of identical twins have also shown that one twin did not develop CD in $25 \%$ of the cases studied [4], supporting the role played by environmental factors in the aetiology of this disorder. However, the elements leading to a breakdown in oral tolerance to gluten in predisposed individuals are as yet unknown. The gut microbiota constitutes a complex pool of antigens separated from the

\section{() Biomed Central}


mucosal immunocompetent cells by just a single layer of epithelial cells. In this mucosal immune system IgA constitutes a first line of defence responsible for neutralizing noxious antigens and pathogens [5]. In fact, malfunction of immune cells of Peyer Patches in production of secretory IgA has been considered a risk factor for CD development [6]. It has also been speculated that a transient infection could promote inflammation and increase permeability of the mucosa to antigens by activating a $T h_{1}$ response with secretion of IFN $-\gamma$, the major pro-inflammatory cytokine in $\mathrm{CD}$ patients $[7,8]$. Moreover, alterations in the intestinal microbiota composition of $C D$ children in comparison with that of healthy controls, as well as changes in the metabolites derived from the gut microbial activity have been recently reported [9-12]. Nevertheless, the possible relationship between the gut microbiota composition and the first line of immune defence in $\mathrm{CD}$ patients remains uncharacterized.

Herein, the percentage of immunoglobulin-coated bacteria and the faecal microbiota composition of children with $C D$ (untreated and treated with a gluten-free diet [GFD]) and controls were evaluated, thus shedding light on the possible associations between the intestinal bacteria and the host defences in this disorder.

\section{Results}

Immunoglobulin-coated bacteria of faeces from $C D$ patients

Immunoglobulin-coated bacteria were quantified in faeces of both $\mathrm{CD}$ patient groups and healthy controls to establish whether $\mathrm{CD}$ could be associated with gut barrier defects or abnormal immune responses to the intestinal microbiota (Figure 1). Overall, higher percentages of IgA, IgM and IgG-coated bacteria were detected in healthy controls than in both $\mathrm{CD}$ patient groups. The proportions of IgA-coated bacteria were significantly lower in untreated $(P=0.018)$ and treated $C D$ patients $(P=0.003)$ than in healthy controls. The proportions of IgG and IgM-coated bacteria were also significantly lower in treated CD patients than in controls $(P<0.001$ and $P=0.003$, respectively) and untreated CD patients $(P<0.001$ and $P=0.009$, respectively). The levels of IgG were also slightly lower in untreated $C D$ patients than in healthy controls but the differences were not significant $(P=0.069)$.

\section{General microbiota composition of faeces from CD patients}

The composition of faecal microbiota of CD patients treated and untreated with a GFD and healthy controls was characterized by using oligonucleotide probes targeting the main bacterial groups colonizing the human gut (Figure 2; Table 1). The three groups of children under study were matched by age considering the variability of the composition of human microbiota during the first years of life. Total Gram-positive bacterial populations were the highest in healthy controls and the lowest in untreated $C D$ patients, while it reached intermediate values in treated $C D$. These differences were statistically significant $(P=0.004)$ between untreated $C D$ patients and controls (Figure 2A). Gram-positive bacterial levels did not normalize completely after a long-term GFD in treated CD patients, although the differences did not reach statistical significance $(P=0.203)$ when compared with controls. Total Gram-negative bacteria reached similar values (ranging from 27.5 to $32.7 \%$ ) in faeces from the three population groups $(P=0.323-0.650$; Figure 2A). The ratio of total Gram-positive to Gramnegative bacteria was the highest in healthy controls and significantly reduced in treated CD patients $(P=0.045)$ and even more in untreated CD patients $(P=0.006)$.

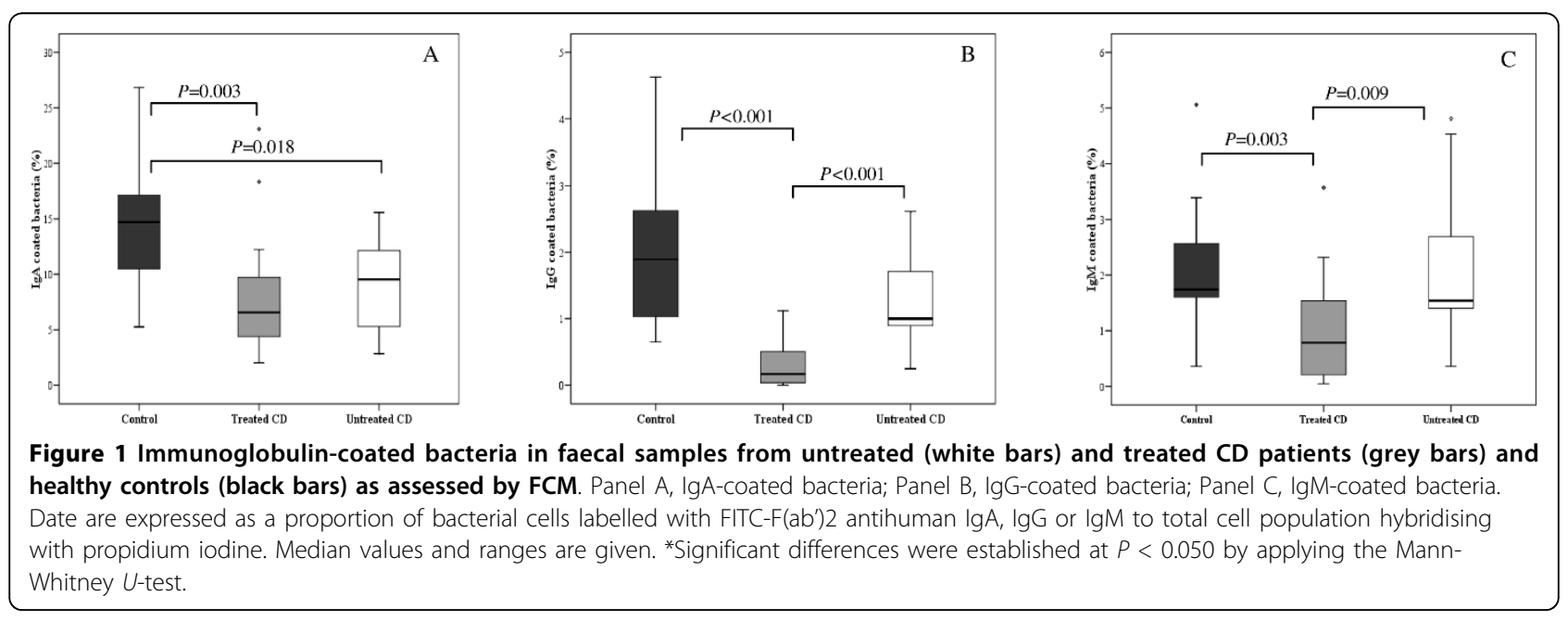




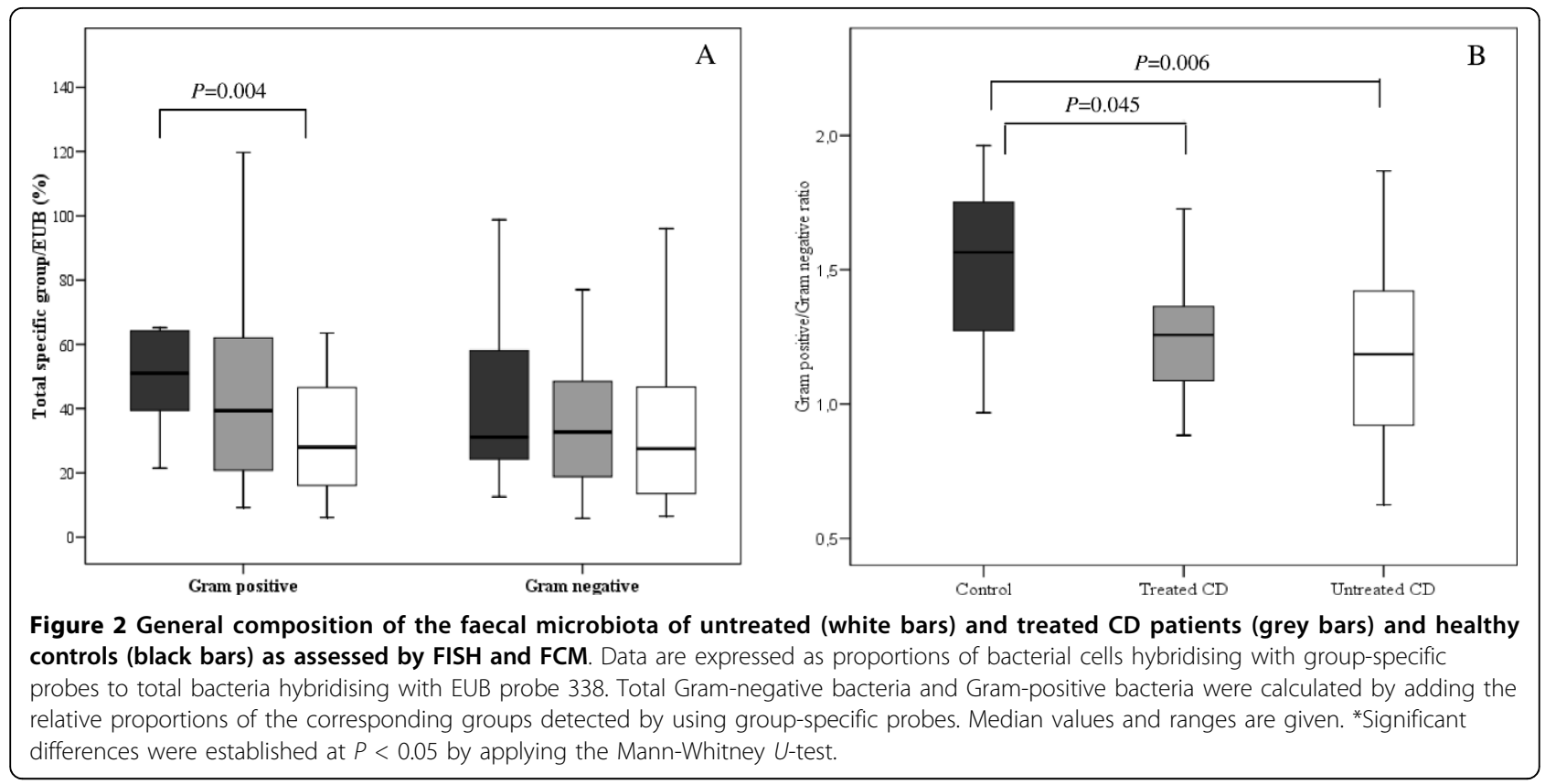

\section{Specific microbiota composition of faeces from CD patients}

The specific group and species composition of the faecal microbiota of $C D$ patients with untreated and treated $C D$ and healthy controls are shown in Table 1 . The highest differences in the relative abundance of specific bacterial groups were found between untreated $C D$ patients and healthy controls, while treated CD patients generally showed intermediate values. Bifidobacterium proportions were significantly lower in untreated $C D$ patients than in healthy controls $(P=0.009)$, while treated $C D$ patients displayed intermediate values. Similarly, the relative abundance of bacteria belonging to C. histolyticum, C. lituseburense and F. prausnitzii groups proved to be significantly lower in untreated $C D$ patients than in healthy subjects $(P=0.031, P=0.024$ and $P=0.045$, respectively), whereas treated CD patients showed intermediate values. The Bacteroides-Prevotella group proportions were significantly more abundant in untreated $C D$ patients than in healthy controls $(P=0.033)$. Escherichia coli, Staphylococcus, Lactobacillus-Enterococcus and sulphate-reducing bacteria reached similar proportions in the three groups of children regardless of their health status.

Immunoglobulin A coating specific bacterial groups in faeces from $C D$ patients

Of the total bacteria, the percentage of IgA coating Bacteroides-Prevotella group was significantly higher in

Table 1 Faecal microbiota composition of untreated and treated CD patients and age-matched healthy controls assessed by FISH and FCM

\begin{tabular}{|c|c|c|c|c|c|c|}
\hline \multirow[t]{3}{*}{ Microbial groups } & \multicolumn{6}{|c|}{ Specific group-probed cells/EUB-388 cells (\%) ${ }^{1}$} \\
\hline & \multicolumn{2}{|c|}{ Untreated CD ( $\mathrm{n}=24)$} & \multicolumn{2}{|c|}{ Treated CD $(n=18)$} & \multicolumn{2}{|c|}{ Control $(n=20)$} \\
\hline & Median & Range & Median & Range & Median & Range \\
\hline Bifidobacterium & 7.73 & $22.08-3.27$ & 9.20 & $33.82-1.58$ & 12.54 & $33.68-6.94$ \\
\hline C. histolyticum & 5.26 & $27.61-0.71$ & 9.41 & $39.60-2.95$ & 11.61 & $35.69-0.16$ \\
\hline C. lituseburense & 3.23 & $27.24-0.17$ & 4.41 & $29.85-0.28$ & 6.83 & $19.56-1.05$ \\
\hline Lactobacillus-Enterococcus & 1.94 & $10.93-0.14$ & 1.12 & $9.30-0.22$ & 1.76 & $16.47-0.25$ \\
\hline Staphylococcus & 10.36 & $37.38-0.89$ & 16.49 & $42.91-0.51$ & 18.04 & $41.32-0.19$ \\
\hline Bacteroides-Prevotella & 3.54 & $20.85-0.80$ & 2.61 & $15.07-0.25$ & 2.32 & $5.53-0.33$ \\
\hline E. coli & 5.20 & $23.42-0.48$ & 6.39 & $28.77-0.55$ & 7.32 & $28.26-1.10$ \\
\hline F. prausnitzii & 6.03 & $37.50-1.07$ & 11.09 & $37.84-2.95$ & 13.88 & $37.08-2.32$ \\
\hline Sulphate-reducing bacteria & 9.58 & $38.02-2.84$ & 9.82 & $41.74-2.09$ & 10.02 & $36.92-2.92$ \\
\hline
\end{tabular}

${ }^{1}$ Data were expressed as proportions of bacterial cells hybridising with group-specific probes to total bacteria hybridising with EUB probe 338.

* Statistical significant differences were calculated using the Mann-Whitney $U$-test and established at $P<0.050$. 
healthy patients than in untreated $C D$ patients $(P=0.014)$ and treated CD patients $(P=0.019)$. A $10.93 \%$ (6.13-20.13) of Bacteroides-Prevotella group from healthy patients was IgA-coated, while a $4.24 \%$ (4.68-6.54) and a $4.97 \%(0.88-8.34)$ was IgA-coated in untreated and treated $C D$ patients, respectively. Accordingly, within the Bacteroides-Prevotella population, the percentage which was coated with IgA was significantly higher in healthy controls $(69.02 \%$; 40.5481.61) than in untreated CD $(P=0.033)(25.42 \%$; 7.09 55.09), while no differences were detected with treated CD patients. No differences were found in the proportion of IgA coating the Bifidobacterium group between $C D$ patients and healthy controls. The percentage of IgA-coated Bifidobacterium was higher $(P<0.05)$ than that of IgA-coated Bacteroides-Prevotella in all groups of children.

\section{Discussion}

This study has characterized faecal microbiology and immunoglobulin-associated features in active and nonactive stages of $\mathrm{CD}$ in children and in age-matched controls with an aim to furthering our understanding of the interplay between the gut microbiota and the host defences in this disorder. Immunoglobulin secretions constitute a primary line of defence of the mucosal surface against noxious antigens and pathogens, and contribute to the intestinal homeostasis preventing clinical inflammation. The colon predominantly harbours IgAsecreting plasma cells (90\%); moreover, $4 \%$ cells secrete IgG and $6 \%$ cells secrete IgM. A considerable percentage of faecal bacteria was coated with IgA (14.71\%) in healthy individuals, whereas a lower bacterial percentage was coated with IgG and IgM, and a similar trend was observed in CD patients, as reported in other subjects [13]. Significantly lower levels of IgA-coated bacteria were detected in faecal samples of untreated and treated $\mathrm{CD}$ patients when compared to healthy controls. It can be speculate that these results could reflect the existence of a barrier defect in $\mathrm{CD}$ patients, which fails to stabilise the gut microbiota and prevent the host from the invasion of harmful antigens and pathogens. In addition, treated $C D$ patients showed lower levels of IgG and IgM coated bacteria. In contrast, IBD patients displayed a higher percentage of immunoglobulincoated faecal bacteria in active disease and shortly after remission, supporting the concept that the mucosal tolerance to the gut microbiota is deregulated in these patients [5].

A remarkable reduction in Gram-positive bacterial populations was characteristic of the active phase of the disease while its abundance was partially restored in patients under a GFD. In addition, a reduction in the ratio of Gram-positive to Gram-negative bacteria was found in the patients regardless of the phase of the disorder. The levels of total Gram-positive bacteria were also lower in duodenal biopsies of patients with active and inactive $\mathrm{CD}$ than in controls, while the proportions of total Gram-negative bacteria were overrepresented particularly in biopsies of active $C D$ patients [12]. Therefore, the results obtained first in biopsies and now in faeces from children of the same age confirm similar structural changes in the composition of the gut microbiota associated with $\mathrm{CD}$. The reductions in beneficial Gram-positive bacteria could favour the residence and interactions of harmful Gram-negative bacteria within the mucosal surface of CD patients, thereby contributing to loss of gluten tolerance. Antigenic structures of Gram-negative bacteria such as flagellins and lipopolysaccharides have been related to the inflammatory responses and pathogenesis of IBD [14]. Shifts in the intestinal microbiota, characterized by increases in pro-inflammatory Gramnegative bacteria, have also been shown to aggravate murine colitis via activation of acute inflammation through Toll-like receptor signalling [15].

Of the specific bacterial groups analysed, the Bifidobacterium population was significantly reduced in faecal samples of untreated CD patients as compared with controls. Bifidobacterium populations significantly decreased or slightly decreased in faeces of IBD patients, as detected by cultural techniques and real time PCR, respectively [16]. The benefits obtained by administering some Bifidobacterium strains as part of probiotic mixtures or symbiotics (probiotics combined with prebiotics) in ulcerative colitis and pouchitis also support the notion that this bacterial group is relevant to IBD [17]. C. histolyticum, C. lituseburense and F. prausnitzii groups were present in higher proportions in healthy individuals than in CD patients; particularly, the abundance of $C$. histolyticum followed a similar trend to that found in biopsy specimens although the differences were not significant [12]. C. coccoides and C. leptum groups were lower in faeces of Crohn's disease and ulcerative colitis patients when determined by real-time PCR [16]. A depletion of F. prausnitzii population in faecal mucus of active Crohn's disease, but not in ulcerative colitis, has also been detected [18]. Comparative analysis of biopsy and faecal samples of IBD patients, based on genomiclibrary sequencing analysis, also showed reductions in Firmicutes belonging to the class Clostridia in active and in remission Crohn's disease patients as compared to healthy or ulcerative colitis groups $[19,20]$. Although some studies are controversial, it appears that the presence of certain Clostridium groups and F. prausnitzii is deficient in luminal or mucosa-associated microbiotas of Crohn's disease and probably of CD patients too. 
These components of the microbiota are producers of butyrate, which is an important energy source for colonocytes and exerts anti-inflammatory effects, for instance by inhibiting the lipopolysaccharide-induced cytokine response [19]. In contrast, the BacteroidesPrevotella group was found in higher proportions in untreated $C D$ patients than in controls, as previously detected in duodenal biopsy specimens [12]. Associations between the phylum Bacteroidetes and Crohn's disease were revealed by comparative bacteriological analysis of biopsy specimens of Crohn's disease and ulcerative colitis patients by denaturing gradient gel electrophoresis (DGGE) [17]. Similar comparative analyses of the mucosal-associated microbiota by genomic-library sequencing of $16 \mathrm{~S}$ rRNA genes showed increases in Proteobacteria and Bacteroidetes, particularly in Crohn's disease patients [19]. Nevertheless, a recent study reported that $B$. fragilis and $B$. vulgatus were found at lower levels in faeces of IBD patients when compared to those of healthy controls [16].

As Bacteroides and Bifidobacterium seem to be possible relevant bacterial groups to $C D$, specific percentages of IgA coating these two bacterial groups were also determined. Interestingly, the proportions of IgA-coated Bacteroides-Prevotella were higher in healthy individuals than in treated and untreated CD patients, suggesting an increased defensive response of the gut mucosal immune system to this bacterial group in healthy children than in CD patients. The combination of an increased proportion of BacteroidesPrevotella group in faecal samples of CD patients together with a weaker defensive IgA response could explain the recurrent relationship found between $\mathrm{Bac}$ teroides and inflamed gut mucosa in $C D[12,21]$, although more direct evidence is needed to confirm this hypothesis. A higher percentage of IgA-coated Bifidobacterium than IgA-coated Bacteroides-Prevotella was detected in all groups of children, similarly to other studies [5]. This could be a consequence of an increased interaction between the gut mucosal immune system and this bacterial group [5], which contributes to mucosal tolerance towards high gut Bifidobacterium concentrations.

\section{Conclusions}

This study confirms that in CD patients there is an alteration in the type of faecal immunoglobulin-coated bacteria that is associated with a shift in the structure of the microbiota. In particular, increases in the relative abundance of Bacteroides-Prevotella group are paralleled to reductions in the IgA coating this group, which could suggest a reduction of of the host defences against this bacterial group. However, the possible clinical consequences of these finding are still unknown and their elucidation would require further investigations.

\section{Methods \\ Subjects}

Altogether 62 children were included in the study: 24 untreated $C D$ patients (mean age 5.5 years, range 2.1-12.0 years) on a normal-gluten containing diet, showing clinical symptoms and signs of the disease, positive CD serology markers (anti-gliadin antibodies and anti-transglutaminase antibodies) and signs of severe enteropathy by duodenal biopsy examination classified as type 3 according to Marsh classification of CD; 18 treated CD patients (mean age 5.5 years, range 1.0-12.3 years) on a gluten-free diet for at least 2 years, without symptoms of the disease, showing negative $C D$ serology markers and normal mucosa architecture; and 20 healthy children (mean age 5.3 years, range 1.8-10.8 years) without known gluten intolerance.

None of the children were treated with antibiotics at least 1 month before to the faecal sampling. The study was conducted in accordance with the ethical rules of the Helsinki Declaration (Hong Kong revision, September 1989), following the EEC Good Clinical Practice guidelines (document 111/3976/88 of July 1990) and current Spanish law, which regulates clinical research in humans (Royal Decree 561/1993 regarding clinical trials). Children were enrolled in the study after written informed consent obtained from their parents.

\section{Faecal sample preparation}

Faeces from the three groups of children were collected in sterile plastic boxes, frozen immediately after collection at $-20^{\circ} \mathrm{C}$, and stored until analysed. Faeces were diluted 1: $10(\mathrm{w} / \mathrm{v})$ in PBS (pH 7.2) and homogenized in a Lab Blender 400 stomacher (Seward Medical London, UK) for $5 \mathrm{~min}$. After low-speed centrifugation $(2,000 \mathrm{~g}$, $2 \mathrm{~min}$ ), the supernatant was collected. For bacterial quantification, cells were fixed by adding $4 \%$ paraformaldehyde solution (Sigma, St Louis, MO) and incubated overnight at $4^{\circ} \mathrm{C}$. After fixation, bacteria were washed twice in PBS by centrifugation $(13,400 \mathrm{~g}$ for $5 \mathrm{~min})$. Finally, cell pellets were suspended in a PBS/ethanol mixture $(1: 1)$ and stored at $-80^{\circ} \mathrm{C}$ until analyzed as previously described [12].

\section{Immunoglobulin-coated bacterial analysis}

Bacterial cells from $20 \mu \mathrm{l}$ of the supernatant obtained after low-speed centrifugation were collected $(12,000$ $\mathrm{rpm}$ for $5 \mathrm{~min})$. The pellet was resuspended in $60 \mu \mathrm{l} 1 \%$ (w/v) BSA/PBS, containing 1\% (v/v) FITC-labelled F(ab') 2 antihuman IgA, IgG or IgM (CALTAG Laboratories, Burlingame, CA). Another aliquot of each sample was pelleted and resuspended in $60 \mu \mathrm{l} 1 \%(\mathrm{w} / \mathrm{v}) \mathrm{BSA} / \mathrm{PBS}$ 
Table 2 Oligonucleotide probes and hybridisation conditions used in the analysis of faecal bacteria by FISH and FCM

\begin{tabular}{|c|c|c|c|c|}
\hline Probe & Target Bacterial group & Sequence $\left(5^{\prime}-3^{\prime}\right)$ & Hybridisation Conditions $\left({ }^{\circ} \mathrm{C}\right)$ & References \\
\hline Eub 338 & Domain bacteria & GCT GCC TCC CGT AGG AGT & 50 & [13] \\
\hline Non 338 & Negative control & ACA TCC TAC GGG AGG C & 50 & [14] \\
\hline Bif 164 & Bifidobacterium & CAT CCG GCA TTA CCA CCC & 50 & [24] \\
\hline Lab 158 & Lactobacillus/Enterococcus & GGT ATT AGC A(C/T)C TGT TTC CA & 45 & [25] \\
\hline Bac 303 & Bacteroides/Prevotella & CCA ATG TGG GGG ACC Tा & 45 & {$[26]$} \\
\hline Ecol 1513 & Escherichia coli & CAC CGT AGT GCC TCG TCA TCA & 50 & [27] \\
\hline Chis 150 & Clostridium histolyticum & TTA TGC GGT ATT AAT CT(C/T) CCT TT & 50 & {$[28]$} \\
\hline C Lis 135 & Clostridium lituseburense & GTT ATC CGT GTG TAC AGG G & 50 & {$[28]$} \\
\hline FPrau 645 & Faecalibacterium prausnitzii & CCT CTG CAC TAC TCA AGA AAA AC & 50 & [29] \\
\hline SRB 687 & Sulphate-reducing bacteria & TAC GGA TTT CAC TCC T & 50 & {$[30]$} \\
\hline STA & Staphylococcus & TCC TCC ATA TCT CTG CGC & 50 & [31] \\
\hline
\end{tabular}

and used as control. After $30 \mathrm{~min}$ incubation, suspensions were washed twice with PBS. Bacterial pellet was finally resuspended in $500 \mu \mathrm{l}$ PBS and mixed with $20 \mu \mathrm{l}$ propidium iodine $\left(100 \mathrm{mg} \mathrm{l}^{-1}\right)$ to label total bacteria before flow cytometry detection [5]. To determine the percentage of IgA coating the Bacteroides-Prevotella and Bifidobacterium groups, the hybridised bacteria were resuspended in $60 \mu \mathrm{l} 1 \%(\mathrm{w} / \mathrm{v}) \mathrm{BSA} / \mathrm{PBS}$, containing $1 \%$ (v/v) FITC-labelled $\mathrm{F}(\mathrm{ab}$ ') 2 antihuman IgA (CALTAG Laboratories, Burlingame, CA). After 30 min incubation, suspensions were washed twice with cold PBS, stored at $4^{\circ} \mathrm{C}$ in the dark and analysed within few hours, as previously described [5].

\section{Microbiological analysis by fluorescent in situ hybridisation}

The bacterial groups present in faeces were quantified by fluorescent in situ hybridization (FISH) using group-specific probes (MOLBIOL, Berlin, Germany). The specific probes and controls used in this study, as well as the hybridization conditions, are shown in Table 2. In the case of $E$. coli a $50^{\circ} \mathrm{C}$ hybridization temperature was used. The EUB 338 probe, targeting a conserved region within the bacterial domain, was used as a positive control [22] and the NON 338 probe was used as a negative control to eliminate background fluorescence [23]. Control probes were covalently linked at their 5' end either to indocyanine dye $\mathrm{Cy} 3$ or to fluorescein isothiocyanate (FITC). Specific cell enumeration was performed by combining each of the group-specific FITC-probes with the EUB 338Cy3 probe as previously described [12]. Briefly, fixed cell suspensions were incubated in the hybridization solution $\left(10 \mathrm{mmol} \mathrm{l}^{-1}\right.$ Tris- $\mathrm{HCl}, 0.9 \mathrm{~mol} \mathrm{l}^{-1} \mathrm{NaCl} \mathrm{pH}$

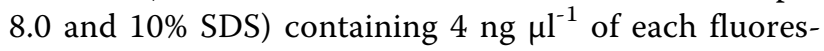
cent probe at appropriate temperatures, overnight. Then, hybridised cells were pelleted by centrifugation $(12,000 \mathrm{rpm}$ for $5 \mathrm{~min})$ and resuspended in $500 \mu \mathrm{l}$ PBS solution for flow-cytometry analysis.

\section{Flow cytometry}

Flow cytometry detections were performed using an EPICS XL-MCL flow cytometer (Beckman Coulter, Florida, USA) as previously described [12]. This instrument is equipped with two light scatter detectors that measure forward (FSC) and side scatter (SSC) and fluorescence detectors that detect appropriately filtered light at green (FL1, $525 \mathrm{~nm}$ ) and red-orange (FL3, $620 \mathrm{~nm}$ ) wavelengths. The event rate was kept at the lowest setting (200-300 events per second) to avoid cell coincidence. A total of 15,000 events were recorded in a list mode file and analyzed with the System II V.3 software (Beckman Coulter). The proportion of each bacterial group was expressed as a ratio of cells hybridising with the FITC-labelled specific probe to cells hybridising with the universal EUB 338-Cy3 probe [12]. Total Gram-negative bacteria and Gram-positive bacteria were calculated by adding the relative proportions (\% specific group/EUB) of the corresponding groups. Immunoglobulin-coated bacteria was expressed as a ratio of bacterial cells labelled with FITC-labelled F(ab')2 antihuman IgA, IgG or IgM to the bacterial cell populations hybridising with either propidium iodine, EUB338 probe, Bacteroides-Prevotella group-specific probe or Bifidobacterium group-specific probe [5].

\section{Statistical analyses}

Statistical analyses were done using the SPSS 11.0 software (SPSS Inc, Chicago, IL, USA). Due to non-normal distribution, microbial and immunoglobulin coating bacterial data are expressed as medians and ranges (maximum-minimum values). The differences between two groups of samples were determined by applying the Mann-Whitney $U$ test. In every case, a $P$-value $<0.05$ was considered statistically significant.

\section{Abbreviations}

CD: Coeliac disease; Ig: Immunoglobulin; HLA: Human Leukocyte Antigen; FCM: Flow cytometry; FISH: Fluorescence in situ hybridization; GFD: Glutenfree diet; IBD: Inflammatory bowel disease. 


\section{Acknowledgements}

This work was supported by grant AGL2007-66126-C03-01 and Consolider Fun-C-Food CSD2007-00063 from the Spanish Ministry of Science and Innovation (MICINN, Spain). The postdoctoral scholarship to MM from MICINN, the scholarship to IN from Generalidad Valenciana (Spain) and CSIC (Ref 200570F0091), and to GDP from CSIC are fully acknowledged.

\section{Author details}

${ }^{1} E$ Ecofisiología Microbiana y Nutrición, Instituto de Agroquímica y Tecnología de Alimentos (CSIC), Apartado 73, 46100 Burjassot, Valencia, Spain. ${ }^{2}$ Hospital Universitario La Fe, Avenida Campanar 21, 40009 Valencia, Spain. ${ }^{3}$ Hospital General Universitario, Avenida Tres Cruces s/n 46014 Valencia, Spain.

\section{Authors' contributions}

GDP, IN and MM carried out the microbiological and immunoglobulin analyses, ED, CRK and MC participated in the recruitment and clinical examination of the studied children. YS conceived of the study and draft the manuscript. All authors read and approved the final version of the manuscript.

Received: 29 September 2009 Accepted: 24 February 2010 Published: 24 February 2010

\section{References}

1. Drago S, El Asmar R, Di Pierro M, Grazia Clemente M, Tripathi A, Sapone A, Thakar M, lacono G, Carroccio A, D'Agate C, Not T, Zampini L, Catassi C, Fasano A: Gliadin, zonulin and gut permeability: Effects on celiac and non-celiac intestinal mucosa and intestinal cell lines. Scand J Gastroenterol 2006, 41:408-419.

2. Green PH, Jabri B: Celiac disease. Annu Rev Med 2006, 57:207-221.

3. Mearin ML, Ivarsson A, Dickey W: Coeliac disease: is it time for mass screening? Best Pract Res Clin Gastroenterol 2005, 19:441-452.

4. Greco L, Romino R, Coto I, Di Cosmo N, Percopo S, Maglio M, Paparo F, Gasperi V, Limongelli MG, Cotichini R, D'Agate C, Tinto N, Sacchetti L, Tosi R, Stazi MA: The first large population based twin study of coeliac disease. Gut 2002, 50:624-628.

5. van der Waaij $L A$, Kroese FG, Visser A, Nelis GF, Westerveld BD, Jansen PL, Hunter JO: Immunoglobulin coating of faecal bacteria in inflammatory bowel disease. Eur J Gastroenterol Hepatol 2004, 16:669-674.

6. Mulder SJ, Mulder-Bos GC: Most probable origin of coeliac disease is low immune globulin $A$ in the intestine caused by malfunction of Peyer's patches. Med Hypotheses 2006, 66:757-762.

7. Barbato M, lebba V, Conte MP, Schippa S, Borrelli O, Maiella G, Longhi C, Totino V, Viola F, Cucchiara S: Role of gut microbiota in the pathogenesis of celiac disease. Dig Liver Dis 2008, 40:A42.

8. Sanz Y, Sánchez E, De Palma G, Medina M, Marcos A, Nova E: Indigenous gut microbiota, probiotics, and coeliac disease. Child Nutrition \& Physiology New York: Nova Science Publishers, IncOverton LT, Ewente MR 2008, 211-224

9. Tjellström B, Stenhammar L, Högberg L, Fälth-Magnusson K, Magnusson KE, Midtvedt T, Sundqvist T, Norin E: Gut microflora associated characteristics in children with celiac disease. Am J Gastroenterol 2005, 100:2784-2788.

10. Sanz Y, Sanchez E, Marzotto M, Calabuig M, Torriani S, Dellaglio F: Differences in faecal bacterial communities in coeliac and healthy children as detected by PCR and denaturing gradient gel electrophoresis. FEMS Immunol Med Microbiol 2007, 51:562-568.

11. Collado MC, Calabuig M, Sanz Y: Differences between the fecal microbiota of coeliac infants and healthy controls. Curr Issues Intest Microbiol 2007, 8:9-14.

12. Nadal I, Donat E, Ribes-Koninckx C, Calabuig M, Sanz Y: Imbalance in the composition of the duodenal microbiota of children with coeliac disease. J Med Microbiol 2007, 56:1669-1674.

13. van der Waaij $L A$, Limburg PC, Mesander $G$, van derWaaij $D$ : In vivo IgA coating of anaerobic bacteria in human faeces. Gut 1996, 38:348-354.

14. Pastor RO, Lopez San RA, Albeniz AE, de la Hera MA, Ripoll SE, Albillos MA: Serum lipopolysaccharide-binding protein in endotoxemic patients with inflammatory bowel disease. Inflamm Bowel Dis 2007, 13:269-277.

15. Heimesaat MM, Bereswill S, Fischer A, Fuchs D, Struck D, Niebergall J, Jahn HK, Dunay IR, Moter A, Gescher DM, Schumann RR, Göbel UB, Liesenfeld O: Gram-negative bacteria aggravate murine small intestinal
Th1-type immunopathology following oral infection with Toxoplasma gondii. J Immunol 2006, 177:8785-8795.

16. Takaishi H, Matsuki T, Nakazawa A, Takada T, Kado S, Asahara T, Kamada N, Sakuraba A, Yajima T, Higuchi H, Inoue N, Ogata H, Iwao Y, Nomoto K, Tanaka R, Hibi T: Imbalance in intestinal microflora constitution could be involved in the pathogenesis of inflammatory bowel disease. Int J Med Microbiol 2008, 298:463-472.

17. Bibiloni R, Fedorak RN, Tannock GW, Madsen KL, Gionchetti P, Campieri M, De Simone C, Sartor RB: VSL\#3 probiotic-mixture induces remission in patients with active ulcerative colitis. Am J Gastroenterol 2005, 100:1539-1546.

18. Swidsinski A, Loening-Baucke V, Vaneechoutte M, Doerffel Y: Active Crohn's disease and ulcerative colitis can be specifically diagnosed and monitored based on the biostructure of the fecal flora. Inflamm Bowel Dis 2008, 14:147-161

19. Gophna U, Sommerfeld K, Gophna S, Doolittle WF, Veldhuyzen van Zanten SJ: Differences between tissue-associated intestinal microfloras of patients with Crohn's disease and ulcerative colitis. J Clin Microbiol 2006, 44:4136-4141.

20. Manichanh C, Rigottier-Gois L, Bonnaud E, Gloux K, Pelletier E, Frangeul L, Nalin R, Jarrin C, Chardon P, Marteau P, Roca J, Dore J: Reduced diversity of faecal microbiota in Crohn's disease revealed by a metagenomic approach. Gut 2006, 55:205-211.

21. Collado MC, Donat E, Ribes-Koninckx C, Calabuig M, Sanz Y: Specific duodenal and faecal bacterial groups associated with paediatric coeliac disease. J Clin Pathol 2009, 62:264-269.

22. Amann Rl, Binder BJ, Olson RJ, Chisholm SW, Devereux R, Stahl DA Combination of $16 \mathrm{~S}$ rRNA-targeted oligonucleotide probes with flow cytometry for analyzing mixed microbial populations. Appl Environ Microbiol 1990, 56:1919-1925.

23. Wallner G, Amann R, Beisker W: Optimizing fluorescent in situ hybridization with rRNA-targeted oligonucleotide probes for flow cytometric identification of microorganisms. Cytometry 1993, 14:136-143.

24. Langendijk PS, Schut F, Jansen GJ, Raangs GC, Kamphuis GR, Wilkinson MH, Welling GW: Quantitative fluorescence in situ hybridization of Bifidobacterium spp. with genus-specific $16 \mathrm{~S}$ rRNA-targeted probes and its application in fecal samples. Appl Environ Microbiol 1995, 61:3069-3075.

25. Harmsen HJM, Elfferich P, Schut F, Welling GW: A 165 rRNA-targeted probe for detection of lactobacilli and enterococci in faecal samples by fluorescent in situ hybridisation. Microbiol Ecol Health Dis 1999, 11:3-12.

26. Manz W, Amann R, Ludwig W: Application of a suite of $16 \mathrm{~S}$ rRNA-specific oligonucleotide probes designed to investigate bacteria of the phylum cytophaga-flavobacter-bacteroides in the natural environment. Microbiol 2006, 142:1097-1106.

27. Poulsen LK, Lan F, Kristensen CS, Hobolth P, Molin S, Krogfelt KA: Spatia distribution of Escherichia coli in the mouse large intestine inferred from rRNA in situ hybridization. Infect Immun 1994, 62:5191-5194.

28. Franks AH, Harmsen HJ, Raangs GC, Jansen GJ, Schut F, Welling GW: Variations of bacterial populations in human feces measured by fluorescent in situ hybridization with group-specific $16 \mathrm{~S}$ rRNA-targeted oligonucleotide probes. Appl Environ Microbiol 1998, 64:3336-3345.

29. Suau A, Rochet V, Sghir A, Gramet G, Brewaeys S, Sutren M, Rigottier-Gois L, Doré J: Fusobacterium prausnitzii and related species represent a dominant group within the human fecal flora. Syst Appl Microbiol 2001, 24:139-145.

30. Bullock NR, Booth JC, Gibson GR: Comparative composition of bacteria in the human intestinal microflora during remission and active ulcerative colitis. Curr Issues Intest Microbiol 2004, 5:59-64.

31. Kempf VA, Trebesius K, Autenrieth IB: Fluorescent In situ hybridization allows rapid identification of microorganisms in blood cultures. I Clin Microbiol 2000, 38:830-838.

doi:10.1186/1471-2180-10-63

Cite this article as: De Palma et al:: Intestinal dysbiosis and reduced immunoglobulin-coated bacteria associated with coeliac disease in children. BMC Microbiology 2010 10:63. 